\title{
DESIGN PARA A SUSTENTABILIDADE NO CICLO DE VIDA DE EMBALAGENS DE DELIVERY: ALTERNATIVAS PARA AMENIZAR IMPACTOS AMBIENTAIS NO CENÁRIO PANDÊMICO NA CIDADE DE UBERLÂNDIA -MG.
}

ISABELLA GOMES DE MARCO, M.SC. | UFU

VIVIANE G. NUNES, Dra. |UFU

CLÁUDIO PEREIRA DE SAMPAIO, Dr.| UEL

\section{INTRODUÇÃO}

O novo Coronavírus (COVID-19) é um agente biológico que está enquadrado alto risco individual e moderado risco para a comunidade se disseminados, podendo se propagar de pessoa para pessoa. Para evitar a proliferação de patologias, estão sendo estabelecidas medidas de tratamento ou de prevenção, como o isolamento, distanciamento social e fechamentos graduais do comércio para a não dispersão do vírus. (ABES, 2020). Por meio de levantamento documental, esta pesquisa mostra que o fechamento do comércio na cidade de Uberlândia pode ter elevado a demanda de pedidos de alimentos e refeições via delivery e, consequentemente, salientado o volume de Resíduos Sólidos de Embalagens oriundas destes serviços (figura 1).

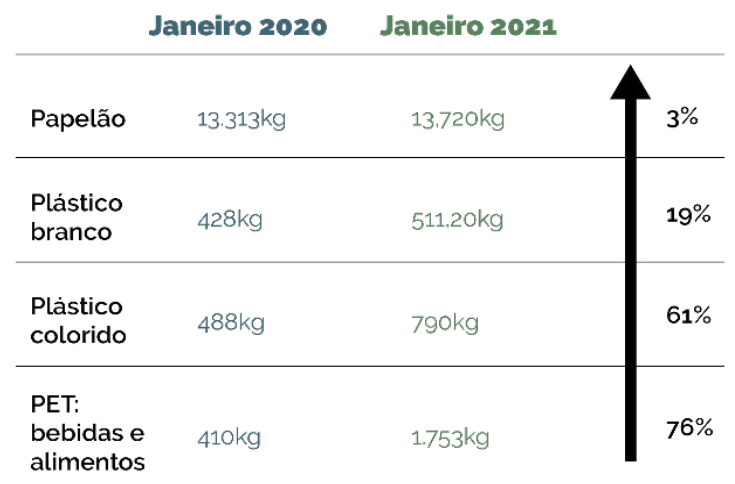

Figura 1 - Comparação do volume de RSU em Uberlândia

Fonte: Elaborado pelos autores com base no Relatório da Cooperativa de Uberlândia (CORU)

É crucial assimilar os materiais envolvidos no processo de produção dessas embalagens de delivery, uma vez que em sua maioria suas composições prejudicam um desenvolvimento ambiental sustentável. Por isso, esta pesquisa segue o objetivo de elaborar estratégias para melhoramento ambiental e de segurança de saúde no Ciclo de Vida das Embalagens de Delivery que apresentam maior recorrência no período pandêmico na cidade de Uberlândia a partir da abordagem do Design para a Sustentabilidade (D4S).

A metodologia desta pesquisa é apoiada por duas fases: Análise e Coleta de dados e redesenho D4S. De acordo com a UNEP (2009), o Design para a Sustentabilidade (D4S):

- orienta estratégias de inovação para aliviar os impactos ambientais, sociais e econômicos negativos no ciclo de vida de produtos e serviços (UNEP, 2009).

- é baseada em todo o ciclo de vida de um produto ou serviço em consideração ao avaliar os impactos de sustentabilidade, ou seja, vai além de fazer um produto 'verde' - e se esforça para atender necessidades do consumidor por meio de intervenções orientadas para a sustentabilidade de forma sistêmica.

Como resultado, pretende-se:

(i) Conseguir conciliar a metodologia selecionada e comprovar ou negar conjecturas sobre a situação das embalagens de delivery na pandemia; (ii) Entender quais ideias podem ser implementadas no Ciclo de Vida dos resíduos de embalagem de delivery e agregar maiores ganhos ambientais e sociais para o município de Uberlândia; (iii) Entender que tipo de proposta terá melhor funcionalidade e aplicabilidade; (iv) Realizar as fases do redesenho D4S bem como efetuar uma validação com versão revisada da proposta a partir de considerações de especialistas e/ou usuários; (v) Documentar hipóteses que possam ser úteis em estudos posteriores. 


\section{REFERÊNCIAS}

ABES - Associação brasileira de engenharia sanitária e ambiental. Recomendações para a gestão de resíduos em situação de pandemia por coronavírus (covid-19). 2020

UNEP, Design for Sustainability. A Step-by-Step Approach, United Nations Environment Programme, 2009

CORU (b) - Cooperativa de Recicladores de Uberlândia. Relatório de controle de coleta. Uberlândia, 2020.

CORU (a) - Cooperativa de Recicladores de Uberlândia. Relatório de controle de coleta. Uberlândia, 2021. 